\title{
Efeito da presença e do número de indivíduos de Pontoscolex corethurus (Glossoscolecidae, Oligochaeta) sobre a populaçào total de microorganismos do solo.
}

\author{
Rafael Torquemada Guerra ( $\left.{ }^{*}\right)$ \\ Neuza Asakawa $\left({ }^{* *}\right)$
}

\begin{abstract}
Resumo
Para verificar se, na Amazônia, as minhocas exercem a mesma influência sobre os microorganismos do solo constatada em outras regiōes tropicais e temperadas, foi feita a contagem do número total de microorganismos do solo em cubas contendo diferentes números de minhocas. Foi observado que a presença de minhocas, independente do seu número, fez aumentar a população microbiana no decorrer do tempo. Este aumento deve-se ao fornecimento de um substrato (matéria orgânica) que proporciona energia e principalmente, ao aparecimento dos excrementos das minhocas em todo o perfil das cubas.
\end{abstract}

\section{INTRODUÇÃo}

Muitos trabalhos têm sido publicados sobre o efeito das minhocas (Annelida, Oligochaeta) nos microorganismos do solo, e entre eles encontramos um bom número de trabaIhos contraditórios. Admite-se atualmente que o trato digestivo das minhocas contém as mesmas espécies de microorganismos existentes no solo em que estas vivem (Satchell, 1958, 1971). Segundo Parle (1963), em solos inoculados com minhocas, o número de fungos e leveduras varia pouco, após passarem pelo intestino das minhocas, porém as bactérias e actinomicetos aumentam exponencialmente após a passagem pelo intestino. Ponomareva, (1953) afirma que há um aumento no número de actinomicetos, bactérias pigmentadas e outras bactérias do grupo Bacillus cereus, após passarem pelo intestino das minhocas. Zrazhevski (1957 apud Edwards \& Lofty, 1977) observou que a densidade da população bacteriana em um solo gramado (turf soil) sem presença de minhocas era de $2,8 \times$
$10^{6} \mathrm{~g}$; entretanto nos excrementos das minhocas adicionadas a esse solo, era de $9,8 \times 10^{6} / \mathrm{g}$ e, no mesmo solo após uma longa colonização por minhocas, era também de $9,8 \times 10^{6} / \mathrm{g}$, ou seja, 3 vezes superior à densidade inicial. Atlavinyte \& Lugauskas (1971) afirmam que as minhocas aumentam até cinco vezes o número de microorganismos edáficos. Isto é então, uma ótima evidência de que as minhocas são importantes na inoculação de microorganismos no solo e de que seus excrementos são focos para a disseminaçăo destes microorganismos. Levando isso em consideração e sabendo-se do importante papel que os microorganismos desempenham no solo, tanto na decomposição da matéria orgânica, como nos ciclos de nutrientes, tais como o de nitrogênio e fósforo, propusemo-nos a verificar se essa influência ocorre na Região Amazônica uma vez que a maior parte dos trabalhos foi realizado em regiōes temperadas, e para isso utilizamos Pontoscolex corethurus (Glossoscolecidae, Oligochaeta) espécie de minhoca pantropical e de maior abundância em nossa região.

\section{MAteriaIS E MÉTOdOS}

O experimento foi realizado durante os meses de julho a setembro/80 em casa de vegetação telada. Utilizamos 5 cubas plásticas contendo cada uma, 10 quilos de terra (Latossolo Amarelo textura pesada com aproximadamente um ano após a queima) e aproximadamente 1 quilo de composto orgânico (excremento bovino e restos de verduras triturados). As cubas foram forradas com folhas se-

(*) - Universidade Federal do Acre (UFAc) - Aluno de Fós-Graduaçăo em Ecologia/INPA/FUA.

$\left({ }^{* *}\right)$ - Instituto Nacional de Pesquisas da Amazônia, Manaus.

ACTA AMAZONICA 11(2): 319-324. 1981 
cas no fundo e sobre a terra, para proporcionar um ambiente aproximadamente ideal para as minhocas (Roth, 1969). A cuba 1 serviu como testemunha. $\mathrm{Na}$ cuba, 2 foram colocados dez exemplares de $P$. corethurus, na cuba 3 . vinte exemplares, na 4 , trinta e na cuba 5 , quarenta exemplares.

As cubas foram regadas de 3 em 3 dias e foi acompanhada diariamente a variação da temperatura máxima nas cubas.

Foi feita uma contagem inicial do número total de microorganismos do solo antes de colocarmos as minhocas e, a seguir, a contagem foi feita quinzenalmente, durante 2 meses.

O total de microorganismos de cada tratamento foi contado pelo método das diluições sucessivas.

De cada tratamento, amostras de terra foram tiradas de 5 pontos ao acaso e juntadas numa única amostra. Uma grama desta amostra foi misturada em $9 \mathrm{ml}$ de solução salina $(0,8 \% \mathrm{NaCl} ; 0,1 \%$ Calgon) contendo bolinhas de vidro, sendo então agitadas durante dois minutos em agitador elétrico. Essa solução foi diluída em série (até a $60^{\circ}$ diluição), colocando $1 \mathrm{ml}$ da suspensão em $9 \mathrm{ml}$ da solução salina seguinte $e$, usadas para a contagem, somente as diluiçōes $10^{-4}, 10^{-5}$ e $10^{-6}$ face à alta concentração de microorganismos nas diluições anteriores.
De cada diluição foi transferido $0,1 \mathrm{ml}$ da suspensão para o centro de uma placa estéril, com pipeta esterilizada. A seguir, foram adicionados $20 \mathrm{ml}$ de "meio extrato de solo agar", liquefeito à temperatura de $45^{\circ} \mathrm{C}$, e misturando-o com o inoculante com movimentos circulares. O meio utilizado não é seletivo e permite o crescimento tanto de bactérias, como de fungos e actinomicetos e, continha a seguinte composição para 1 litro de água destilada: $1 \mathrm{~g}$ glicose; $0,5 \mathrm{~g} \mathrm{~K} \mathrm{HPO}_{4} ; 0,1 \mathrm{~g} \mathrm{KNO} ; 100$ $\mathrm{ml}$ extrato de solo; $15 \mathrm{~g}$ agar; $\mathrm{pH}$ acertado para 7,0 .

Foram feitas 3 repetições, para cada diluição e 3 placas, contendo somente o meio como controle.

As placas foram mantidas em estufa à temperatura de $30^{\circ} \mathrm{C}$ e, após uma semana de incubação, foi feita a contagem total dos microorganismos da diluição, em que se desenvolveram de 30 a 300 colônias por placa.

A análise estatística aplicada foi a análise de variância de blocos casualizados. Todas as diferenças são analisadas a nível de $5 \%$.

\section{RESULTADOS}

Conforme mostra a Tabela 1, houve um aumento de 2 a 5 vezes, no número total de microorganismos do solo após o acréscimo de

TABELA 1 - Número total de microorganismos do solo em relação a tempo de Incubação com diferentes números de minhocas (Média em relação a tempo de coleta e número de minhocas)

\begin{tabular}{|c|c|c|c|c|c|c|}
\hline \multirow{3}{*}{$\begin{array}{l}\text { Número de } \\
\text { Minhocas }\end{array}$} & \multicolumn{5}{|c|}{ Tempo de Incubação (dias) } & \multirow[b]{3}{*}{$\bar{x}$} \\
\hline & 0 & 15 & 30 & 45 & 60 & \\
\hline & \multicolumn{5}{|c|}{ Número de Microorganismos $\times 10^{\delta} /$ grama de solo seco } & \\
\hline 0 & 1,87 & 17,69 & 13,77 & 13,20 & 10,92 & 11,49 \\
\hline 10 & 3,17 & 24,48 & 20,04 & 55,56 & 21,06 & 24,86 \\
\hline 20 & 3,48 & 36,56 & 76,99 & 55,73 & 46,22 & 43,79 \\
\hline 30 & 3,64 & 63,80 & 34,12 & 26,32 & 12,05 & 29,98 \\
\hline 40 & 3,83 & 55,17 & 56,46 & 95,31 & 47,78 & 51,71 \\
\hline $\bar{x}$ & 3,20 & 39,54 & 40,27 & 51,22 & 26,70 & \\
\hline
\end{tabular}


minhocas, assim como um aumento de aproximadamente 10 a 15 vezes, no decorrer do tempo de incubação.

Um número maior de microorganismos do solo ocorreu nas cubas com 20 e 40 minhocas (Tabela 1) diferindo significativamente da cuba testemunha (Tabela 2). O diferente número de minhocas presentes nas cubas, apesar de proporcionar um aumento na população microbiana, este não foi significativo, com exceção da cuba com 40 minhocas em relação à cuba com 10 minhocas (Tabela 2).

O crescimento do número total de microorganismos em relação ao tempo de incubação apresentou-se significativamente diferente entre o momento da contagem e as coletas subsequentes, como mostra a Tabela 3 . Após 15 dias de incubação, houve um aumento considerável, de 10 vezes, e observa-se um aumento gradativo no decorrer do tempo, com uma queda brusca após 60 dias (Tabelas 1 e 3 ).

As temperaturas máximas registradas nas cubas, no decorrer do experimento mostram que as cubas com minhocas sempre apresentaram um valor superior ao da cuba testemunha (Gráfico 1), embora essa diferença não fosse significativamente diferente.

TABELA 2 - Análise de variância do efeito de número de minhocas no número total de micoorganismos do solo (a nível de $5 \%$ ).

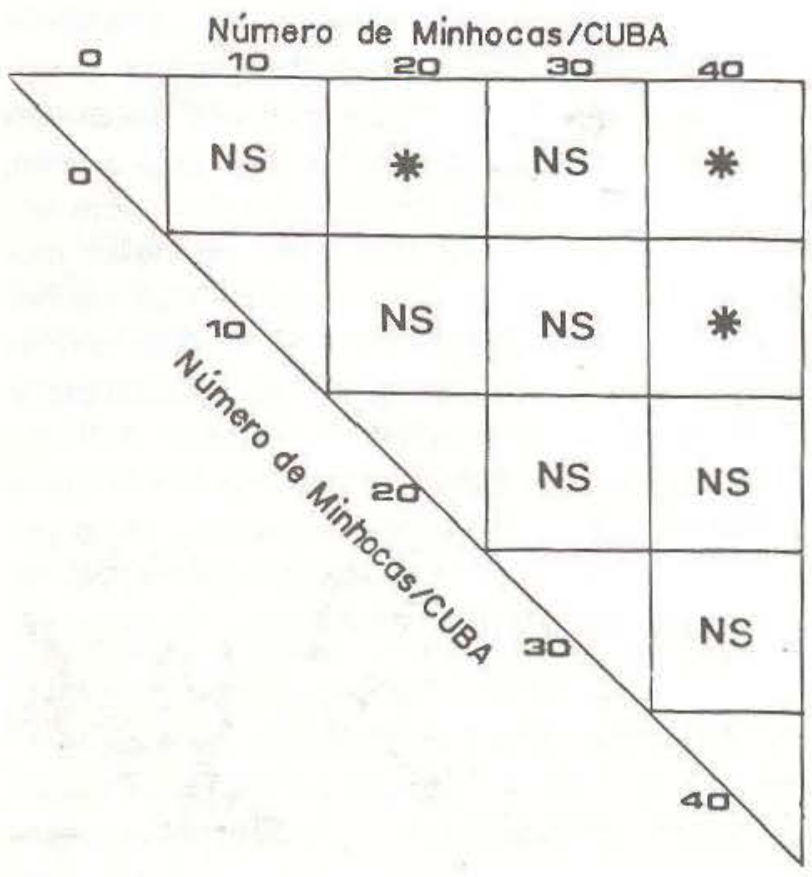

TABELA 3 - Análise de variância do efeito de tempo de incubação com diferentes números de minhocas no número total de microorga nismos do solo (a nível de $5 \%$ ).

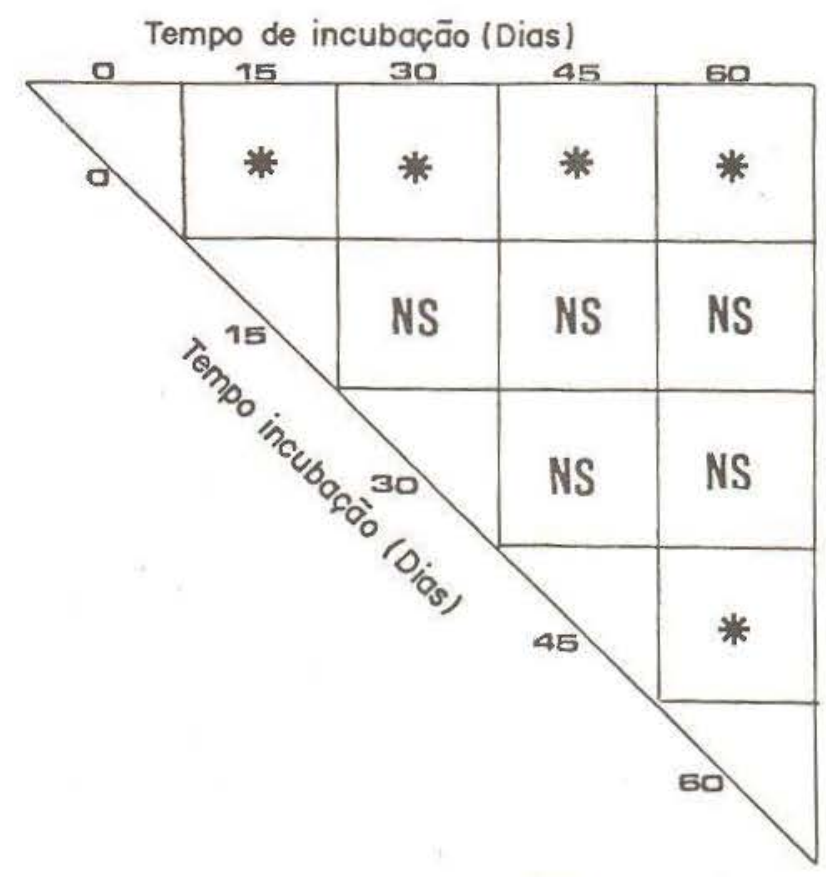

Discussão E CONCLUSÕES

No solo, estão presentes muitos microorganismos e na maioria das vezes, desempenhando as principais funções na eliminação de nutrientes para o crescimento de plantas (Gray \& Williams, 1971).

Os microorganismos do solo compreendem uma diversidade de bactérias, fungos, actinomicetos, algas, pertencentes a inúmeros gêneros e espécies, que estão presentes em grandes quantidades, podendo atingir desde $10^{6}$ ou menos, a alguns bilhões de células de bactérias em uma grama de solo (Gray \& Williams, 1971). As extrapolações de numerosos dados sugerem que as densidades das populações de fungos e actinomicetos também estão dentro de faixas semelhantes (Drozdowicz, 1976).

Dada a grande variação taxonômica e principalmente fisiológica da populaçāo microbiana, não há uma metodologia adequada para medir-se com exatidão, a sua população, mas pode ter-se uma estimativa (Clark, 1971). Neste trabalho, o número total de microorganismos do solo foi estimado pelo método de 


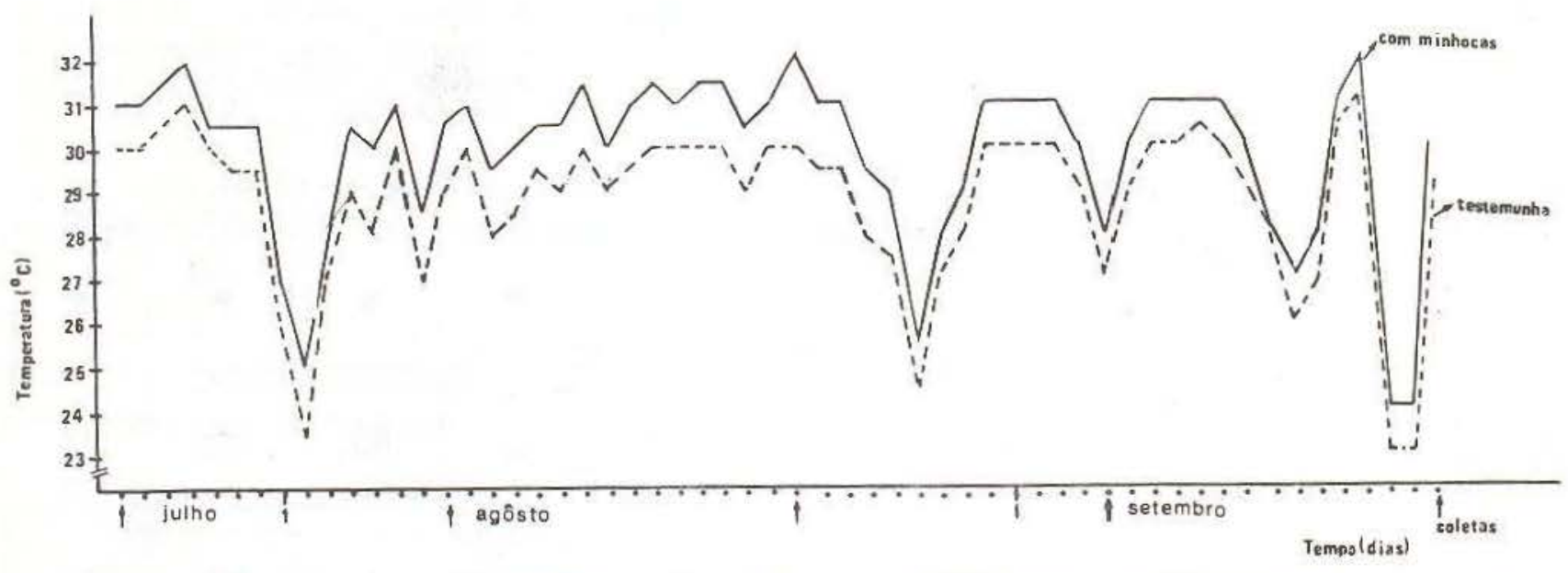

Fig. 1 - Gráfico das temperaturas máximas registradas no decorrer do experimento.

cultivo, usando-se a técnica de diluições sucessivas em placas. Esta técnica supōe que cada célula viável presente na suspensão do solo usado como inoculante, se desenvolverá em uma colônia visivel durante a incubação, apesar de ser impossivel preparar qualquer tipo de combinação de substrato e de condições de incubação que permita o crescimento de todas as espécies presentes (Clark, 1971).

Os números de microorganismos presentes em cada tratamento variaram em torno de $10^{6}$ células por grama de solo, com efeito positivo da presença de minhocas e de tempo de incubação.

Há muitos fatores no solo, naturais ou introduzidas pelo homem, que afetam diferentes espécies de microorganismos de uma forma distinta. Sendo a maioria dos microorganismos heterótrofos, a falta de alimento ou de uma fonte de energia apropriada e disponivel, é o principal fator que limita o seu crescimento (Clark, 1971). Qualquer aumento na matéria orgânica disponivel, capaz de fornecer energia, faz com que haja um aumento no número de microorganismos (Russel \& Russel, 1959). Isto foi verificado no nosso experimento, em que 15 dias após a incubação somente com a matéria orgânica, houve um aumento na população microbiana de aproximadamente 10 vezes (Tabela 1). A fauna do solo, por estar em movimento, distribui a matéria orgânica em decomposição e parte da população microbia- na nas camadas do solo, nas quais desenvolve suas funções, pois ingere alimento em um lugar, mistura-o com bactérias em seu intestino, e, a seguir, este é excretado em outro lugar (Russel \& Russel, 1959), permitindo assim, uma distribuição tanto da fonte de alimento como de microorganismos. Essa distribuição de matéria orgânica em decomposição e também de excrementos de minhocas foi verificada em toda extensão das cubas que continham minhocas.

Os excrementos das minhocas possuem grande quantidade de matéria orgânica numa forma parcialmente digerida e facilmente assimilável pelos microorganismos (Satchell, 1971). A população microbiana nesses excrementos é muito maior do que nos solos circundantes e isso pode ocorrer por uma alimentação seletiva dos materiais que fornecem um substrato para a sua atividade, ou pelas mudanças que ocorrem no intestino das minhocas. O aumento da microflora nestes excrementos vai depender muito da quantidade e do tipo do material vegetal e de solo ingerido pela minhoca. Ainda segundo Satchell (1971). independentemente do material ingerido, o número de bactérias e de actinomicetos presentes nesse material aumenta consideravelmente no intestino das minhocas.

Ghilarov (1963) afirma que os excrementos das minhocas são focos de disseminação dos microorganismos do solo. Ao serem des- 
montadas as cubas com minhocas foi verificada a presença de excrementos tanto no fundo como distribuídas em toda a camada do solo.

Podemos então afirmar que o aumento verificado na população microbiana total do solo nas cubas com minhocas deve-se a estes dois fatores: à presença de excrementos em toda a camada da terra e em menor grau, ao deslocamento da matéria orgânica em profundidade.

Neste trabalho, foi observado que a presença de minhocas independente do seu número, teve uma ação predominante na população microbiana, principalmente no decorrer do tempo. O fornecimento natural de novas quantidades de nutrientes, aliados a boas condições físicas e químicas, manteve o crescimento bacteriano num rítmo dinâmico. O menor aumento verificado na última coleta pode ser atribuído à queda da temperatura.

A escala de temperatura ótima para o desenvolvimento das bactérias do solo encontrase entre $25^{\circ}$ a $35^{\circ} \mathrm{C}$ (Clark, 1971). Os solos tropicais podem ter uma temperatura alta durante todo o ano, variando sempre em torno de 28 a $35^{\circ} \mathrm{C}$ e nesses solos a temperatura abaixo do ótimo para as bactérias dá-se ocasionalmente e, no momento da sua ocorrência, é limitante para a atividade bacteriana (Clark, 1971). Acompanhando o gráfico da temperatura (Gráfico 1) nos dois dias antes da última coleta, a temperatura máxima registrada foi de 23 e $24^{\circ} \mathrm{C}$, portanto abaixo do ponto ótimo esperado para as espécies tropicais.

Um outro fator que pode explicar essa queda no número de microorganismos é o provável acúmulo de metabólitos prejudiciais ao desenvolvimento destes. Esse acúmulo poderia levar ao decréscimo na curva de crescimento no decorrer do tempo. Esse decréscimo pode ser provocado também por escassez de alimento e espaço.

Podemos então concluir que o fornecimento de um substrato (matéria orgânica) capaz de proporcionar energia, faz crescer a população de microorganismos do solo. Além disso, a presença de minhocas, espalhando ao acaso essa matéria orgânica e seus excrementos proporciona novos locais para o crescimento da população microbiana, fazendo com que esta cresça de maneira não localizada no solo. Aliando-se esses fatores ao bom manejo do solo e do cultivo, podem criar-se condições favoráveis para a obtenção de práticas agrícolas com um melhor aproveitamento dos recursos naturais.

\section{SUMMARY}

In order to examine if in Amazonia, earthworms exert the same influence on soil microorganisms observed in other tropical and temperate regions, counts were made of the total number of soil microorganisms in pots containig soil, organic matter and different number of earthworms. In contrast to the behaviour in pots without worms an increase in the total number of microorganisms was observed in all pots containing worms, but did not vary greatly with worm number. The increase in microbial population was considered principally due to the presence of an organic substrates in the worm casts and in consequence was distributed throughout the soil profile of pots with worms.

\section{AgRADECIMENTO}

Agradecemos a Maria Aparecida de Moura, aluna da Universidade do Amazonas e estagiária do Setor de Microbiologia do Solo/INPA, pela participação, na elaboração deste trabalho.

\section{REFERENCIAS BIBLIOGRAFICAS}

ATLAVINYTE, O. \& LUGAUSKAS, A.

1971 - The effect of lumbricidae on soil microorganisms. Ann. Zool. Ecol. Anim. Special publ., 4: 73-80.

CLARK, F.E.

1971 - Bactérios del suelo. In: Biologia del suelo. BURGES, A. \& RAW, F. eds. Omega S.A., Barcelona, p. 27-66.

DROZDOWICZ, A.

1976 - Equilíbrio microbiológico dos solos de cerrados. In: IV Simpósio sobre o cerrado. coord. Livraria Itatiaia Edit. Ltda. \& EDUSP, p. 233-246. 
EDWARDS, C.A. \& LOFTY, J.R.

1977 - Biology of earthworms. Chapman \& Hall, London, 2." ed., 333 p

GHILAROV, M.S.

1963 - On the interrelations between soil dwelling invertebrates and soil microorganisms. In: Soil Organisms. DOEKSEN, J. \& van der DRIFT, J. ed. North Holland Publish. Co., Amsterdam p. 255-259.

GRAY, T.R.G. \& WILLIAMS, S.T.

1971 - Soil micro-organisms. Longman, London, $240 \mathrm{p}$.

PARLE, J.N.

1963 - A micrabiological study of earthworms casts. J, Gen. Microbiol. 13: 13-23.

PONOMAREVA, S.I.

1953 - The influence of the activity of earthworms on the creation of a stable structure in a sod-podolized soil. Trudy Pochv, Inst. Dokuchaeva, 41: 304-378.

ROTH, A.

1963 - Instrucciones para la cria de lombrices de tierra. IDIA; 253: 37-46.

RUSSELL, E.J. \& RUSSELL, E.W.

1959 - Las condiciones del Suelo y el desarrollo de las Plantas, Aguilar, Madrid, 771 p.

SATCHELL, J.E.

1958 - Earthworms biology and Soil fertility. Soil and Ferti., 21: 209-219.

1971 - Lumbricidos. In: Biologia del Suelo, BURGES, A. \& RAW F. ed. Omega, Barcelona, p. $307-378$.

(Aceito para publicação em 07/05/81) 